\title{
Development of Programmable Relay Switch Using Microcontroller
}

\author{
Paul Zabala ${ }^{1}$, Mary Charlemaine Abas $^{2}$, Patrick Cerna ${ }^{3}$ \\ ${ }^{1}$ Department of Mechatronics Technology, Cebu Technological University, Cebu City, Philippines \\ ${ }^{2}$ Department of Electronics Technology, Federal Technological Institute - University, Addis Ababa, Ethiopia \\ ${ }^{3}$ Department of Information Technology, Federal Technological Institute - University, Addis Ababa, Ethiopia
}

Email address:

paul_zab@yahoo.com (P.Zabala), mcaa@ieee.org (M. Abas), pcerna@ieee.org (P.Cerna)

\section{To cite this article:}

Paul Zabala, Mary Charlemaine Abas, Patrick Cerna. Development of Programmable Relay Switch Using Microcontroller. American Journal of Remote Sensing. Vol. 5, No. 5, 2017, pp. 43-51. doi: 10.11648/j.ajrs.20170505.11

Received: December 28, 2017; Accepted: January 17, 2018; Published: February 5, 2018

\begin{abstract}
Today the rapid advances in electronic technologies have resulted in a variety of new and inexpensive control capabilities. The rapid rise of the internet and accessibility of computer resources also led to the concept of Open Source Software as a means to provide free and transparent access to computer code so that individuals could review, modify, improve, and distribute computer software. One such Open Source Hardware project resulted in the creation of a microcontroller-based development platform called Arduino. The main objective of this research is to develop an arduinobased PRS to be manufactured by small and Medium Enterprises (SME) in Ethiopia. Specifically, it seeks to answer the (1) What are the technical requirements in the development of the PRS (2) What are the basic functional capabilities of the PRS in terms of Combinational Logic Functions and Sequential Control Functions and (3) What is the acceptability level of PRS as perceived by experts in terms of functionality, reliability, usability, maintainability, aesthetics and safety. The study used descriptive experimental methods of research utilizing laboratory techniques and adopted scholarly questionnaires. The methods were appropriate to determine the physical design, components, tools, functions and features needed in the development of the project. Those were extremely useful in the development of the actual circuit, final parts selection, and software programming to ensure a robust design. Two experiment were tested namely Combinational Logic Functions and Sequential Control Functions using the Programmable Relay Switch and it generates acceptable results by passing all the testing condition. It was concluded that the PRS product model has standard functional capabilities comparable to most standard PLC's in the market and it is a cheaper but efficient alternative. It can also be constructed from commercially available parts. Moreover, it can be used for actual industrial applications or as a training module in teaching industrial automation or mechatronics courses.
\end{abstract}

Keywords: Programmable Relay Switch, Programmable Logic Controller, Microcontroller, Arduino, IoT, Remote Sensing

\section{Introduction}

Research and development in the field of automation and control for industrial applications has increased rapidly in the recent years. Along with these developments, new manpower requirements (i.e. new skills and expertise) also arise. It is very important therefore for the education sector to keep up with the latest technologies in the field. However, offering industrial automation and control courses in universities is a major challenge. This is because courses that include instrumentations and automation technologies need a significant budget for the acquisition of such expensive modules and high technology equipment for training. Programmable Logic Controllers (PLC's), in particular, the most widely used control equipment in industrial automation and control, are too expensive for the students to integrate in their automation and control projects.

Looking at the industrial manufacturing side today, the sheer number of PLC applications is enormous nowadays. According to Research and Markets [1], the world's largest market research store, global programmable logic controller (PLC) forecasts market to grow at a CAGR of $5.57 \%$ during the period 2017-2021. Manufacturers today are well aware of 
the advantages of automated process control. Automation leads to higher production rates and increased productivity, more efficient use of materials, better product quality, improved safety, shorter workweeks for labor, and reduced factory lead times. However, investing in high technology automation equipment to enjoy these advantages, requires a very significant budget [2].

Today the rapid advances in electronic technologies have resulted in a variety of new and inexpensive control capabilities. The rapid rise of the internet and accessibility of computer resources also led to the concept of Open Source Software as a means to provide free and transparent access to computer code so that individuals could review, modify, improve, and distribute computer software. One such Open Source Hardware project resulted in the creation of a microcontroller-based development platform called Arduino [3]. As an open-source hardware project, all circuit-board and electronic component specifications, as well as the IDE software, are freely available for anyone to use or modify. As a result, private manufacturers all around the world produce and offer inexpensive, standardized Arduino-compatible hardware with an extensive supply of features and capabilities. Using an Arduino simplifies the amount of hardware and software development because the hardware platform is set up already, especially the fact that it allows programming and serial communication over USB, without the need for an external programmer [3].

Another big advantage is the Arduino IDE which allows software development on all major platforms (Mac, PC, Linux) with an easy-to-use subset of $\mathrm{C} / \mathrm{C}++$. Using therefore this aforementioned new technology, an inexpensive alternative to the PLC is hereby proposed. The basic idea is to design and to develop an arduino-based Programmable Relay Switch (PRS) that is capable of performing the basic functions of most of the PLC's in the market today, at a lesser production cost. This Arduino-based PRS featured in this study will be using an atmel microcontroller. With comparable performances, this microcontroller is much less expensive than Intel and other leading microcontrollers used in many dedicated PLC's.

\section{Related Works}

Fisher, D. K. [4] stated that ease of use, capability, and affordability of sensing and monitoring instrumentation have increased greatly due to rapid advances in electronics and communications technologies. Microcontrollers, microprocessors, and solid-state sensors are commonplace, and are found in most modern household appliances (coffee makers, washing machines, ovens), entertainment devices (televisions, radios, game machines), computer equipment (desktop, notebook, tablet computers), and cellular devices (smartphones). These same electronic components are increasingly being incorporated into environmental sensing and monitoring applications in order to study physical processes, monitor activities, and improve production operations.
Ulaganathan et al, [5] in their study Cost-effective Perturb and Observe MPPT (Maximum Power Point Tracking) Method using Arduino Microcontroller for a Standalone Photo Voltaic System found the use of Digital Signal Processors too expensive. While using PIC is relatively cheaper, coding in PIC for expert systems based MPPT is not easy. These are the driving factors to find a simple and low cost solution. This paper proposes an hardware for MPPT techniques using Arduino Microcontroller which has an added advantage of being an open-source and also its coding resembles a simple $\mathrm{C}$ language. Here Perturb and Observe (P\&O) type of MPPT has been implemented and tested on a Standalone Photo Voltaic (PV) system. The results confirm that maximum power has been extracted by $\mathrm{P} \& \mathrm{O}$ method irrespective of atmospheric temperature and solar irradiance with the Arduino microcontroller.

Araújo, et al [6] with their study Integrating Arduinobased Educational Mobile Robots in ROS shows the great advantages of integrating the platform with ROS middleware, enabling the usage of a wide range of tools and reducing the development time through code reuse. The robots, alongside with Arduino and ROS open-source development tools, present themselves as ideal platforms for educational robotics. Similarly, Fisher, D., et al (2012) in his study "Open-Source Hardware Is a Low-Cost Alternative for Scientific Instrumentation and Research" used the Open Source Hardware project Arduino. Inexpensive sensors and the Arduino development platform were used to develop several inexpensive, automated sensing and data logging systems for use in agricultural and natural resources related research projects. Systems were developed and implemented to monitor soil-moisture status of field crops for irrigation scheduling and crop-water use studies, to measure daily evaporation pan water levels for quantifying evaporative demand, and to monitor environmental parameters under forested conditions. These studies demonstrate the usefulness of automated measurements, and offer guidance for other researchers in developing inexpensive sensing and monitoring systems to further their research.

Aksoz and Saygin [7] presented a study on motor speed control implementation establishing communication between android mobile device and PLC. As a first step for the implementation, firstly Bluetooth communication is established using an android based control software. Later PLC and Bluetooth communication is achieved by a developed mobile phone software. Finally compatibility among mobile phone, PLC and Bluetooth devices is achieved and inverter control is provided by commissioning an analog module for PLC device. Control of asynchronous motor is implemented by this controlled inverter. So that mobile phone is used instead of a controller device for applications requiring motor speed control using PLC.

Aksoz et al [8] also proposes a remote control system based on a user and humanoid robot via Bluetooth. A user can control the robot using an android interface and each part of robot can be moved independently around the robot in a remote location. Providing motor position change in a 
mechanical system and automatic controlling of the data from the measuring instrument reduce process time and reduce loss of labor. The automatic controlling of the data from the measuring instrument is supplied with microprocessor

Many of these recently conducted researches mentioned above show that the arduino board, with its open-source platform, prove to be more flexible, easy-to-use and inexpensive for artists, designers, hobbyists, researchers, and anyone interested in creating interactive objects or environments.

\section{Materials and Methods}

\subsection{Research Design and Methodology}

The study used descriptive experimental methods of research utilizing laboratory techniques and adopted scholarly questionnaires. The methods were appropriate to determine the physical design, components, tools, functions and features needed in the development of the project. Those were extremely useful in the development of the actual circuit, final parts selection, and software programming to ensure a robust design.

Thus, to test the operational functionality of the design, laboratory check sheets were utilized based on the operational requirements. The reliability of the design was further tested using environmental and accelerated testing. Survey questionnaires were developed to seek the perception of the experts/end-users regarding the product's functionality, reliability, usability, maintainability, proficiency, aesthetics, and safety.

\subsection{Materials Used in the Study}

The proposed utilize Arduino Microcontroller with its accompanying shields, sensors, modules and switches among others as shown in Table 1.

\subsubsection{Arduino Mega 2560}

The Mega 2560 is a microcontroller board based on the ATmega2560. It has 54 digital input/output pins (of which 15 can be used as PWM outputs), 16 analog inputs, 4 UARTs (hardware serial ports), a $16 \mathrm{MHz}$ crystal oscillator, a USB connection, a power jack, an ICSP header, and a reset button. It contains everything needed to support the microcontroller; simply connect it to a computer with a USB cable or power it with a AC-to-DC adapter or battery to get started. The Mega 2560 board is compatible with most shields designed for the Uno and the former boards Duemilanove or Diecimila [9].

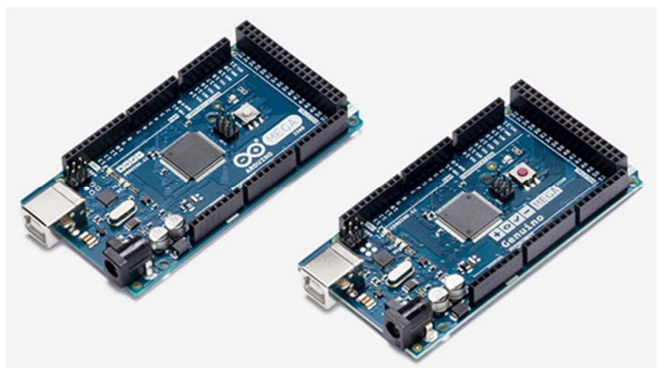

Figure 1. Arduino Mega 2560 Controller.
Table 1. List of Materials.

\begin{tabular}{lll}
\hline$\#$ & Part/Specs & Quantity \\
\hline 1 & Arduino Mega Board & 2 \\
2 & PCB 1 & $86^{\prime \prime}$ \\
3 & Transistors & 6 \\
4 & Relay 6V & 12 \\
5 & Relay 24V & 12 \\
6 & LCD display 16X2 & 2 \\
7 & Terminal 6 pins & 5 \\
8 & Terminal (2 pins) & 12 \\
9 & Plastic Case & 2 \\
10 & IN4001 Diodes & 10 \\
11 & Hook up wires w/ headers & 20 \\
12 & Mini Switches 8pin & 2 \\
13 & 104 mylar & 2 \\
14 & 1000uF 25v & 2 \\
15 & Potentiometer & 2 \\
16 & 1 Kohms 1/4 watt & 20 \\
17 & LM7805 & 1 \\
18 & Heat sink (TO-220) & 1 \\
19 & Masking Tape 1" & 1 \\
20 & Drill Bit 1/32" & 1 \\
21 & Drill Bit 3/16" & 1 \\
22 & Ferric Chloride Bottle & 2 \\
23 & Bolt \& Knots 1/8"X1.5" & 20 \\
24 & Bluetooth Module & 2 \\
25 & Miscellaneous (soldering lead, photo paper, printing, etc.) & \\
\hline & &
\end{tabular}

\subsubsection{Bluetooth Module HC-05}

Arduino Bluetooth $\mathrm{HC}-05$ module is an easy to use Bluetooth SPP (Serial Port Protocol) module, designed for transparent wireless serial connection setup. The HC-05 Bluetooth Module can be used in a Master or Slave configuration, making it a great solution for wireless communication. This serial port bluetooth module is fully qualified Bluetooth V2.0+EDR (Enhanced Data Rate) 3Mbps Modulation with complete $2.4 \mathrm{GHz}$ radio transceiver and baseband. It uses CSR Bluecore 04 - External single chip Rluetooth system with CMOS technology and with AFH [10].
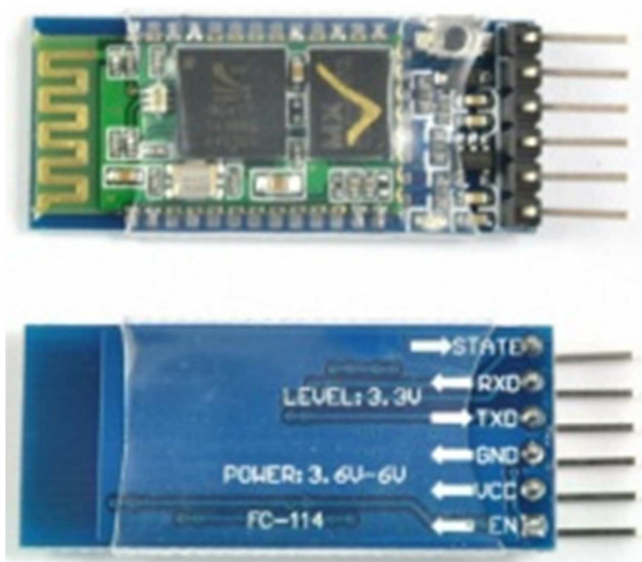

Figure 2. Arduino Bluetooth Module.

\subsubsection{8-Channel 5 and 12 V Relay Board}

It is a relay card that can control contacts with $5 \mathrm{~V}$ and can be used with Arduino or other microcontrollers. It draws a current of $20 \mathrm{~mA}$ during the triggering of the microcontroller. It is an electronic card circuit which is frequently used in 
various industrial and robotics projects. It can switch the current up to 10 Ampere at $30 \mathrm{~V}$ DC or $220 \mathrm{~V}$ AC voltage. There are control leds for each relay. The relays are active with logic $0(0 \mathrm{~V})$ [11].

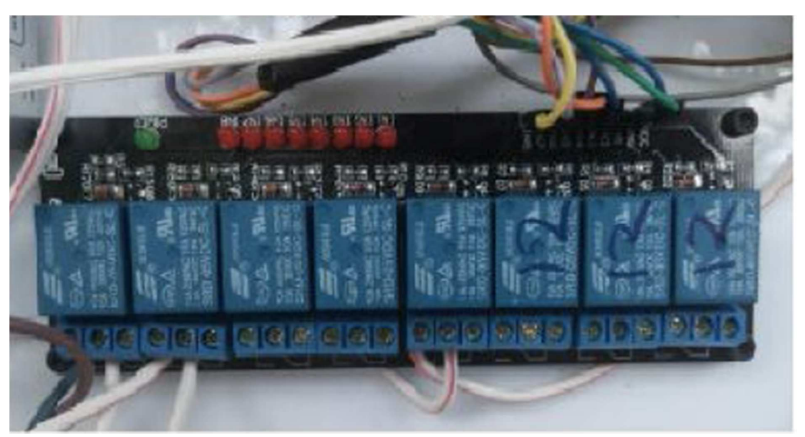

Figure 3. Relay Board.

\subsection{4. $16 x 2$ LCD Display}

$16 \times 2$ LCD Display and Keypad shield can plug directly onto the Arduino and Arduino compatible boards. The LCD panel displays characters in white with a blue backlit and can display up to two lines of 16 characters. The shield includes 6 momentary push button that can be used to implement a 5 buttons keypad including up, down, left, right and select function. The sixth push button brings out the Arduino's reset button to the top of the shield. The $16 \times 2$ LCD Display and Keypad shield interfaces with the Arduino board using digital pin 4 to 10 and analog pin 0 . The contrast can be adjusted via a trim pot and the backlit can be turn on and off. The shield is $5 \mathrm{~V}$ compatible [12].

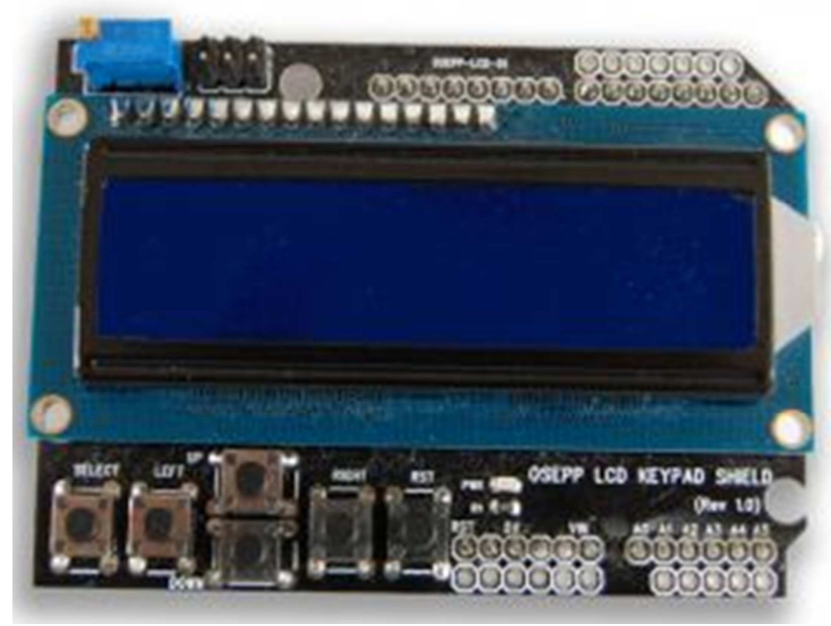

Figure 4. $16 X 2$ LCD Display.

\subsection{Project Design}

\subsubsection{System Flowchart}

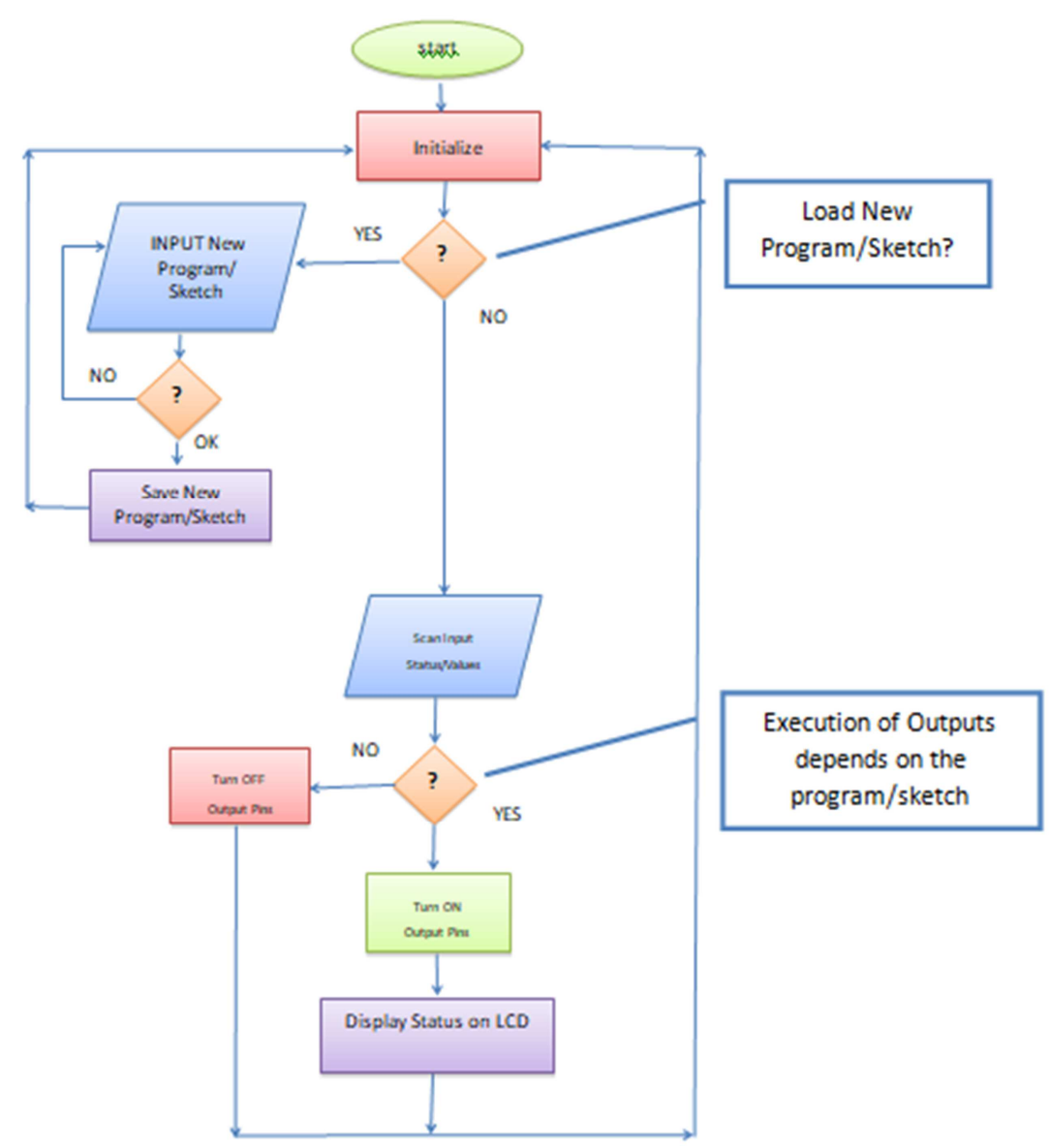

Figure 5. System Flowchart of PRS. 
As shown in Figure 5, the system flowchart upon powering on the PRS, the main microcontroller which is the arduino board, starts to initialize by loading the bootloader code. If the bootloader does not receive a particular sequence of bytes over the serial port, then the processor jumps to the program section to load whatever is already in program memory. Normally, the arduino reads the predefined input pins and then executes the output by turning the predefined output pins high or low depending on the sketch/code. The status of inputs and outputs can also be optionally displayed on the LCD display and the loop is repeated endlessly. If however, the bootloader receives a unique sequence from its serial port, then the byte stream or new code is programmed into the flash. By using the Arduino Integrated Development Environment, one can load a new sketch/code to the PRS. After the loading of the sketch to the arduino board, it will then re-initializes and starts executing again the new sketch/code.

\subsubsection{Block Diagram}

The Block Diagramas reflected in Figure 6 is composed of the main Arduino board, the input, and the output interface circuits. The Input interface circuits are composed of the $24 \mathrm{~V}$
Input relays, the analog input terminals for analog sensors and the optional Bluetooth input Module for wireless control. The output interface circuits are also composed of the transistor drivers for driving the output relays, and the LCD display module for optional display of input and output status.

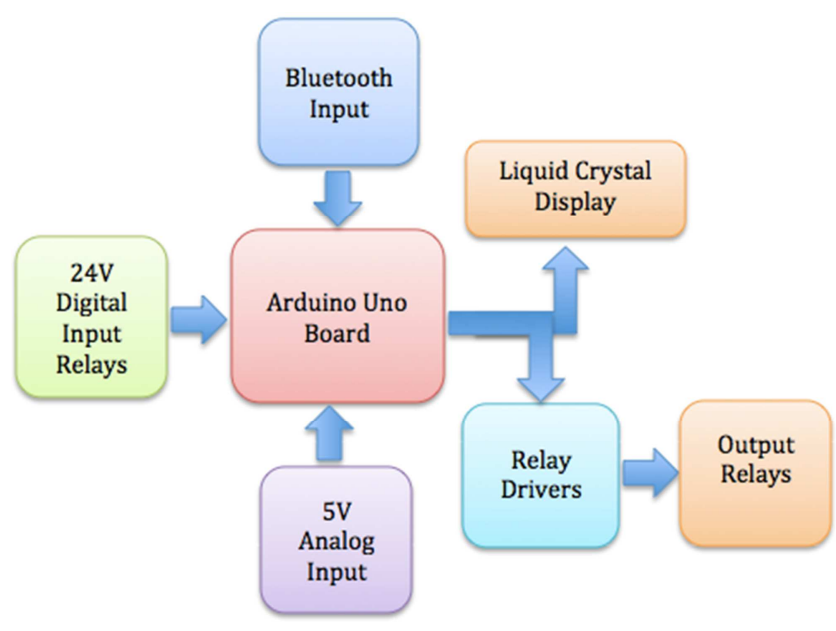

Figure 6. Block Diagram of PRS.

\subsubsection{Schematic Diagram}

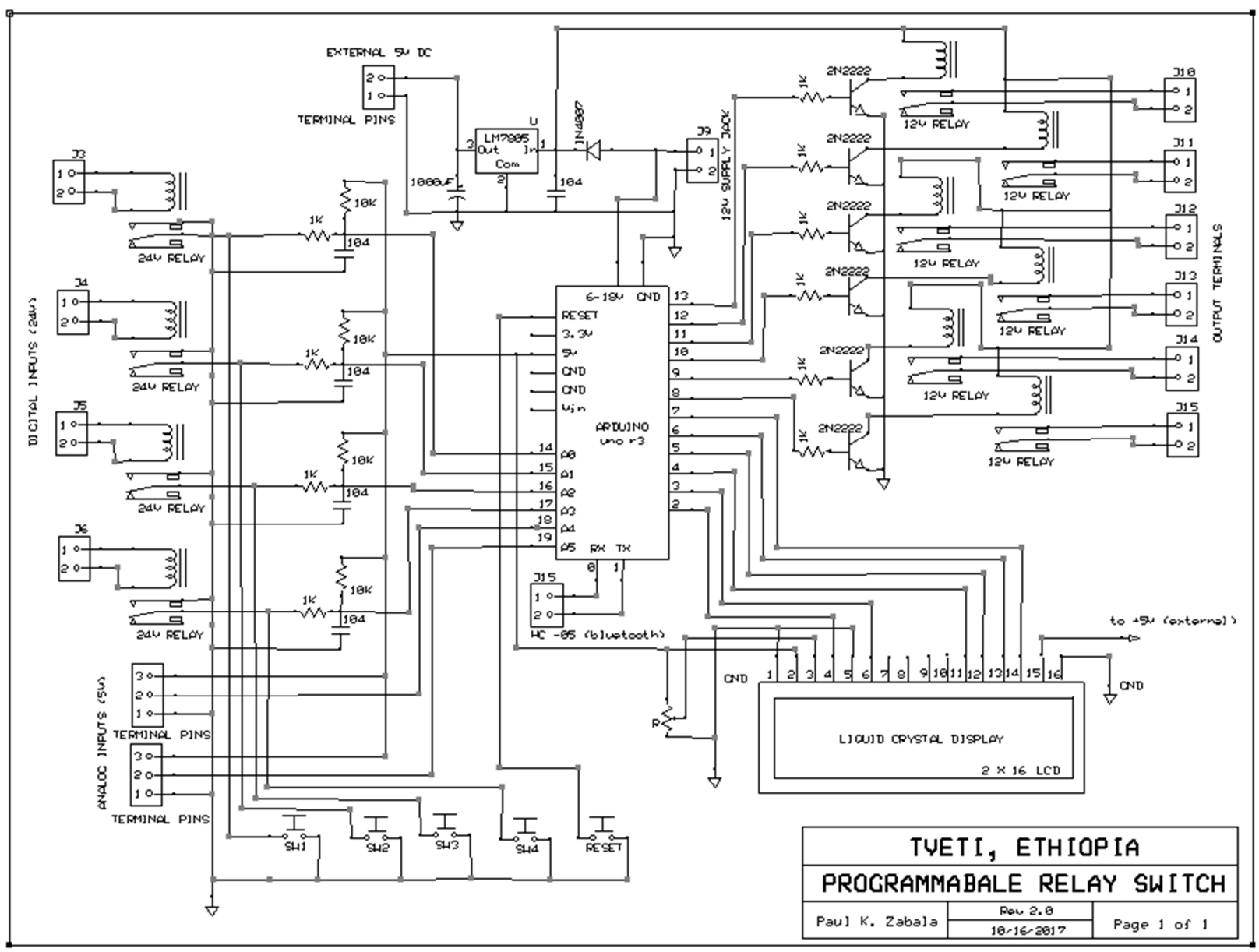

Figure 7. Schematic Diagram of PRS. 
The study came up with the working schematic diagram as reflected in Figure 7, which includes the input and output interface circuits, the power supply and voltage regulator section, the digital/analog selector, the display section, the terminals, and the main controller section comprising of the Arduino board. The digital input interface circuit is composed of four (4) $24 \mathrm{~V}$ electro-mechanical relays, driver transistors and the protection diodes while the analog input is composed of two (2) 3-terminal pins. Another input terminal is reserved for optional bluetooth connection. The power supply and voltage regulator section are composed of the DC jack, reverse polarity protection diodes, the voltage regulator IC, and filter capacitors. The output terminals are composed of two-pin terminals arranged side by side. Another 2-pin terminal is used for the external 5V DC supply coming from the voltage regulator. The Display section is composed of the LCD or the Liquid Crystal Display. Finally, the main controller is composed of the Arduino Uno Board, the main controller of the model

\section{Results and Discussion}

\subsection{Experiments on the Application of PRS}

Two laboratory experiments were conducted to verify the functions of the Programmable Relay Switch based from the common functional requirements of a standard programmable logic controller. Specifically, the experiments were adapted from the laboratory experiment modules from FESTO Didactic Trainings attended by the researcher.

\subsubsection{Experiment No.1 “Combinational Logical Functions"}

This experiment is a combination of several experiments on logical, set-reset priority/latching, and interlocking functions. As an example application model, this can be applied as a 3-Way Interlock System in Electronic Game Arbiters as shown in Figure 8. The same functions are also required to ensure safety in the operations of machines in the industry.

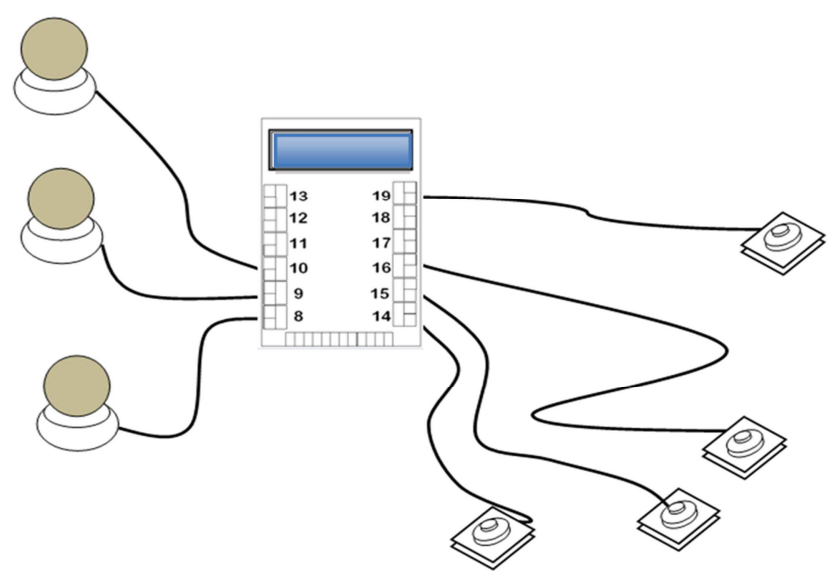

Figure 8. The 3-way Interlock / Game Arbiter.
Test Condition:

$\mathrm{Pb} 1, \mathrm{~Pb} 2$, and $\mathrm{Pb} 3$ are set switches, while $\mathrm{Pb} 4$ is the reset switch. L1, L2, and L3 are output lamps. L1 is to be set by $\mathrm{Pb} 1, \mathrm{~L} 2$ is to be set by $\mathrm{Pb} 2$, while $\mathrm{L} 3$ is to be set by $\mathrm{Pb} 3$. When $\mathrm{Pb} 1$ is activated first, the corresponding output L1 is activated and held active even when PB1 is already released. The circuit then locks by disabling the other set switches $\mathrm{Pb} 2$ and $\mathrm{Pb} 3$. Only $\mathrm{Pb} 4$ can reset the circuit.

On the other hand, if $\mathrm{Pb} 2$ is activated first, the corresponding output L2 is activated and held active even when PB2 has already been released. The circuit then locks by disabling the other set switches $\mathrm{Pb} 1$ and $\mathrm{Pb} 3$. Again only $\mathrm{Pb} 4$ can reset the circuit.

The same process repeats, if $\mathrm{Pb} 3$ is activated first, the corresponding output L3 is activated and held active even when PB3 has already been released. The circuit then locks by disabling the other set switches $\mathrm{Pb} 1$ and $\mathrm{Pb} 2$. Again only $\mathrm{Pb} 4$ can reset the circuit.

\subsubsection{Experiment No.2 "Sequential Control Functions"}

This experiment is a combination of several experiments on auto set-reset, counter up/down and timer on/off functions, which are needed to control automatic and sequential operations in manufacturing processes. As an example, it can be applied as a "Component Washer". An illustration diagram of the application model is shown in Figure 9.

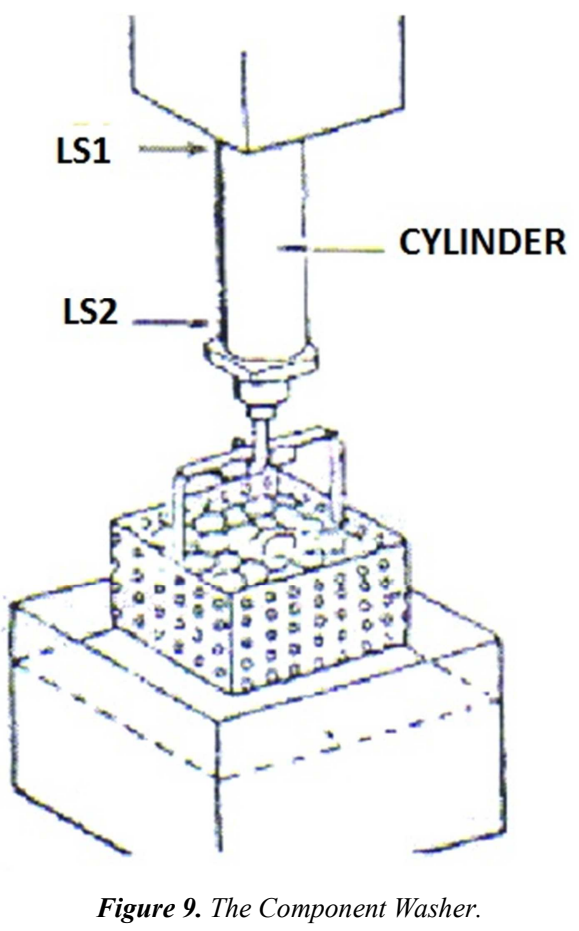

Test Condition:

When start button $\mathrm{Pb} 1$ is pressed cylinder $\mathrm{A}$ extends, as it reaches the limit switch LS2, it will pause for 5 seconds and then retracts to the starting position LS1. It will then pause for another 5 seconds before it extends again repeating the cycle 10 times. 
After the 10th cycle, a buzzer activates for 2 seconds while a light activates permanently until another process starts by pressing $\mathrm{Pb} 1$ again. Another push button $\mathrm{Pb} 2$ stops the process, returns the cylinder to the starting position, and automatically resets the counter.

\subsection{Acceptability on the Application of PRS}

The study adopts purposive sampling method with the target respondents will be the experts and prospective users from both the academe and SME of the final prototype. To determine the acceptability of the project, this study were utilizing a researcher-made questionnaire based on the "The Hierarchy of Design Needs" by William Lidwell, et. al. (Table 2) adapted from the "Hierarchy of Needs" by Abraham Maslow. The questionnaire was based on the perception of the respondents regarding functionality, reliability, usability, aesthetics, and safety of the Programmable Relays as shown on Table 2. The electronic components and circuit diagrams were identified firs and the circuits assembled were experimentally tested in the laboratory according to its requirements. The operational features were also be tested during the programming phase. After the testing and demonstrations, the questionnaires were administered to the respondents to seek for their perceptions toward the prototype.

Table 2. Results of the Acceptability Testing.

\begin{tabular}{ll}
\hline Criteria & Frequency (\%) \\
\hline Functionality & 90 \\
Reliability & 72 \\
Usability & 88 \\
Maintainability & 52 \\
Efficiency & 87 \\
Aesthetics & 52.2 \\
Safety & 70 \\
\hline
\end{tabular}

\subsubsection{Functionality}

On the acceptability level of the PRS with regards to its design and quality, the first to be determined was the functionality of the prototype. The functions identifiedin this study are the most common PLC functions that are utilized in most industrial applications. These are also the same functions that every student must learn when taking up PLC programming courses. In Maslow's Hierarchy of Needs translated to Designing the most basic need of a good design is Functionality. An average of 90 percent of the respondents had rated highly functional. The remaining 10 percent had rated moderately functional. This means that a great majority of the respondents perceived the PRSas having functions comparable to that of a standard programmable logic controller.

\subsubsection{Reliability}

Once a design has met functional needs, it can move up to the next level in the design hierarchy: Reliability. The design should not only work but it must work again and again consistently. In the 8 dimensions of quality by David Garvin, reliable designs successfully perform specified functions for a specified period of time. Also, 72 percent of the respondents rated "highly reliable" while the remaining 24 percent, rated "moderately reliable". Majority of the respondents therefore, believe that the product can work consistently for a longer period of time.

\subsubsection{Usability}

Another feature was rated on the prototype, which is "usability". Usability is the 3rd level in Maslow's Hierarchy of Needstranslated to design. The following questions are based on the basic question: How easily can users accomplish basic tasks with this product 88 percent of the respondents rated "highly usable" while the remaining 12 percent rated "moderately usable". The rating shows thata good majority of the respondents find the PRSeasy to use.

\subsubsection{Maintainability}

Maintainability, also known as serviceability is the speed, courtesy, competence, and ease of repair. It is fifth on the list in the Eight Dimensions of Quality by David Garvin52 percent of the respondents rated the product to be "maintainable", while the remaining 48 percent, rated it to be "moderately maintainable". Although majority of the respondents believe the prototypeis easy to repair slightly lower rating of the prototype as compared to the other features is due to the very compact placement of parts inside the packaging box.

\subsubsection{Efficiency}

Efficient products empower people to do more and to do better at a shorter period of time. 87 percent of the respondents rated "highly efficient", while the remaining 13 percent rated "moderately efficient". After all, the PRS is made to be efficient because it simplifies the amount of hardware and software development. The hardware platform is set up already, especially the fact that it allows programming and serial communication over USB, without the need for an external programmer. The survey results also clearly show these advantages.

\subsubsection{Aesthetics}

Aesthetics is seventh on the list in David Garvin's Eight Dimensions of Quality. It generally refers to how a product looks, feels, sounds, tastes, or smells. It is largely based on a personal judgment and individual preference. 52.2 percent of the respondents rated the aesthetics of the prototype to be "highly acceptable", while the remaining 47.8percent rated "moderately acceptable". This implies that majority of the respondents find the prototype to have a good external design or appearance.

\subsubsection{Safety}

In addition to being easy to use and good in appearance, the design must be forgiving. Consequences for simple mistakes should not be dire. 70 percent of the respondents rated "highly safe", while the remaining 30 percent rated "moderately safe". Most respondents believe that the product is safe to use. In fact, it is using a low voltage power supply of only $5 \mathrm{~V}$ DC. 


\section{Summary}

The following were the most significant findings of this study:

\subsection{On the Technical Requirements}

The study came up with the working schematic diagram, which includes the interface circuits, the power supply and voltage regulator section (Figure 1), the PCB component layout (Figure 2) and the Bill of materials shown in Table 1 and the Tools and equipment Needed in the Construction of the PRS also shown in Table 3. All the materials needed for the construction of the prototype were either purchased locally or on-line.

\subsection{On the Applications of the PRS}

The study adapted and modified the laboratory experiments of the FESTO Didactic PLC training and came up with the combinational logical functional experiment which, as a sample application, it can be applied as a 3 -way interlock system for quiz bowl competitions or for gaming purposes (Figure 3). Another experiment performed is the sequential control function experiment, which as an example, it can also be applied as a component washer in manufacturing industries (Figure 4). Appendix A shows the laboratory sheets with their results.

\subsection{On the Acceptability of the PRS Model}

\subsubsection{Functionality}

The data revealed that the prototype is highly functional as perceived by the experts. And as tested in the laboratory, the PRS is capable of performing combinational logical control and sequential operations control.

\subsubsection{Reliability}

As evaluated by the respondents, the data revealed that the prototype is highly reliable. During the testing, the prototype also performed and complied with the functional requirements.

\subsubsection{Usability}

Although the PRS is not using the usual ladder language for a PLC, the data revealed that the respondents perceived the PRS to be highly usable.

\subsubsection{Maintainability}

Although only 52 percent of the respondents found the PRS to be highly maintainable, while 48 percent rated it to be just moderately maintainable, the average mean shows however, that the product still falls under the rating of "highly maintainable".

\subsubsection{Efficiency}

One of the highest ratings of the PRS model by the respondents is the efficiency. The respondents found it to be highly efficient as it simplifies the amount of hardware and software development. The hardware platform is set up already, especially the fact that it allows programming and serial communication over USB, without the need for an external programmer.

\subsubsection{Aesthetics}

Although aesthetics of the product received a slightly low rating because of its customized packaging, the mean average still shows a highly acceptable rating by the respondents.

\subsubsection{Safety}

With the safety features of the product model, it is perceived to be highly safe to use by the respondents. The model could be utilized as a training module in the academe or as an applied controller in industrial manufacturing operations.

\section{Conclusion}

Based on the above findings, it was concluded that the PRS product model has standard functional capabilities comparable to most standard PLC's in the market and it is a cheaper but efficient alternative. It can also be constructed from commercially available parts. Moreover, it can be used for actual industrial applications or as a training module in teaching industrial automation or mechatronics courses.

It is recommended that the PRS model be adapted and utilized for industrial automation applications. It can also used for instructional purposes in institutions offering industrial automation courses. It is also recommended further that, should it be applied in actual industrial use, a long-term study be conducted to check the durability and life span of the design model.

\section{References}

[1] Research and Markets (2017). Global Programmable Logic Controller (PLC) Market 2017-2021 With Mitsubishi Electric, OMRON, Rockwell Automation, Schneider Electric \& Siemens Dominating. Accessed October 2, 2017.

[2] Britannica (2017). Advantages and disadvantages of automation. Encyclopedia Britannica. Retrieved in https://www.britannica.com/technology/automation/Advantag es-and-disadvantages-of-automation. Accessed March 5, 2017.

[3] Fisher, D. K., Gould, P. J. (2012). Open-Source Hardware Is a Low-Cost Alternative for Scientific Instrumentation and Research. Modern Instrumentation. Vol 1 (2).

[4] Fisher, D. K. (2014). Rapid Deployment of InternetConnected Environmental Monitoring Devices, Advances in Internet Things. Vol (4). 46-54.

[5] Ulaganathan, M. K. D., Saravanan, C., \&Chitranjan, O. R. (2014). Cost-effective Perturb and Observe MPPT Method using Arduino Microcontroller for a Standalone Photo Voltaic System, 8 (1), 24-28.

[6] Araujo, A., Portugal, D., Couceiro, M. S., Rocha, R. P. (2015). Integrating Arduino-Based Educational Mobile Robots in ROS. Journal of Intelligent and Robotic Systems. Vol 77. pp 281-298. 
[7] Aksoz, A., Engin, S., \& Dursun, M. (2016). The Implementation of Controlled Humanoid Robot with Android. Journal of Automation and Control Engineering. Vol4 (3), 225-228. doi:10.18178/joace.4.3.225-228.

[8] Aksoz, A., \& Saygin, A. L. I. (2015). Android mobile devices based automation system. International Journal of Electrical, Electronics and Data Communication. Vol, (3), Issue 3. pp 511.

[9] Arduino (2016). Arduino Mega 2560 Specification. Retrieved from

https://www.arduino.cc/en/main/arduinoBoardMega2560.

Accessed March 2017.
[10] ePro Labs (2017). Bluetooth Module HC-05. Retrieved from https://wiki.eprolabs.com/index.php?title=Bluetooth_Module_ HC-05

[11] Ultimate Robot Part (2017). 12 V 8-Channel Relay Board. Retrieved from http://www.jsumo.com/12v-8-channel-relayboard. Accessed August 15, 2017.

[12] OSEPP (2017). 16 X 2 LCD Display and Keypad Shield. Retrieved from https://www.osepp.com/electronicmodules/shields/45-16-2-lcd-display-keypad-shield\#. Access August 15, 2017. 